\title{
Occupational Asthma Caused by Powder Paint in the Automotive Industry
}

Tiotiu $\mathrm{A}^{1,2,3}$, Thaon $\mathrm{I}^{4}$, Poussel $\mathrm{M}^{2,5}$, Penven $\mathrm{E}^{4}$

${ }^{1}$ Department of Pulmonology, University Hospital of Nancy, Nancy, France

${ }^{2}$ Development, Adaptation and Disadvantage. Cardiorespiratory regulations and motor control (EA 3450 DevAH), University of Lorraine, Nancy, France

${ }^{3}$ National Heart and Lung Institute, Airway Disease Section, Imperial College London, London, UK

${ }^{4}$ Occupational Diseases Department, University Hospital of Nancy, Nancy, France

${ }^{5}$ Department of Pulmonary Function Testing and Exercise Physiology, University Hospital of Nancy, Nancy, France

J Investig Allergol Clin Immunol 2019; Vol. 29(4): 316-318 doi: 10.18176/jiaci.0394

Key words: Occupational asthma. Industry. Aluminum hydroxide.

Palabras clave: Asma ocupacional. Industria. Hidróxido de aluminio.

Occupational asthma (OA) is characterized by variable airflow limitation and/or airway hyperresponsiveness (AHR) associated with inflammation due to causes and conditions attributable to a particular occupational environment and not to stimuli encountered outside the workplace [1]. Diisocyanates are the most common cause of OA in the automotive industry. Powder painting is an alternative to solvent-based spray painting. Triglycidyl isocyanurate [2] and organic acid anhydrides are the main causal agents of OA [3].

We investigated the case of a 41-year-old woman (exsmoker with a 20 pack-year history) who experienced asthma on exposure to powder paint containing aluminum hydroxide. A specific inhalation challenge (SIC) and environmental assessment provided evidence that aluminum hydroxide was the most likely causal agent.

This previously healthy patient (no personal or family history of allergy) had been working for more than 20 years as a control agent in a company specializing in the manufacture of wipers ( 9 years in the packaging section, 11 years in the control department in the proximity of the painting and drying area of the wiper arms). Five-years ago she began to complain of respiratory symptoms (dry cough, dyspnea, and wheezing), which were clearly associated with work-related exposure. Detailed questioning revealed that in her professional environment, she had been indirectly exposed to the powder paint applied to wiper arms, which contained aluminum hydroxide (20\%-25\%). Skin prick tests to aeroallergens and to the powder paint (humidified with water) on a normal reactive skin (negative control, $0 \mathrm{~mm}$; positive control, $7 \mathrm{~mm}$ ) were negative. Her chest computed tomography scan was normal. Functional respiratory tests showed minimal airway obstruction with a forced expiratory volume in the first second $\left(\mathrm{FEV}_{1}\right)$ of $2.59 \mathrm{~L}$ ( $88 \%$ of predicted value), a forced 
vital capacity (FVC) of $3.95 \mathrm{~L}$ (116\% of predicted value), $\mathrm{FEV}_{1} / \mathrm{FVC}$ of 0.66 , total lung capacity (TLC) of $5.10 \mathrm{~L}(99 \%)$, and a transfer factor for carbon monoxide (DLCO) of $75 \%$. The fraction of bronchial exhaled nitric oxide (FeNO), which was measured during a work period, was normal (4.15 ppb). Her controller asthma treatment comprised a fixed combination of formoterol/fluticasone $20 / 500 \mu \mathrm{g} / \mathrm{d}$. The results of a methacholine challenge test during a work period confirmed the presence of AHR, which took the form of a $27 \%$ decrease in $\mathrm{FEV}_{1}\left(2.4 \mathrm{~L}\right.$ at baseline to $1.7 \mathrm{~L}$ for a cumulative dose $\left[\mathrm{PD}_{20}\right]$ of $80 \mu \mathrm{g}$ of methacholine $1 \%$ ) and was associated with asthma symptoms (chest pain, cough, and wheezing) (Figure). Serial monitoring of peak expiratory flow at and away from work over a 3-week period revealed an OASYS score of 3.9 (normal, $<2.5$ ), with a positive predictive value for OA of $83 \%$. SIC was performed with the powder paint 72 hours after controller asthma treatment was stopped. Briefly, the patient was gradually exposed (10 sec, $1 \mathrm{~min}, 5 \mathrm{~min})$ to the powder, and $\mathrm{FEV}_{1}$ was measured after each exposure period. SIC showed an immediate positive reaction at the third step of exposure (ie, $5 \mathrm{~min}$ ) leading to asthma symptoms and a $16 \%$ decrease in $\mathrm{FEV}_{1}$. Values returned to baseline after inhalation of $400 \mu \mathrm{g}$ of salbutamol. No associated ocular or nasal symptoms were present. Monitoring of several parameters before and after SIC revealed induced eosinophilic inflammation in the sputum samples (1\% vs $8 \%$ ) without modification of FeNO (5.93 ppb vs $5.70 \mathrm{ppb})$. The patient was hospitalized for 24 hours for clinical and functional respiratory monitoring (measurement of $\mathrm{FEV}_{1}$ at $30 \mathrm{~min}$ and $60 \mathrm{~min}$ after SIC, and of peak expiratory flow once per $\mathrm{h}$ in the first $6 \mathrm{~h}$, followed by twice daily). She did not experience a late asthmatic reaction. These results confirmed the diagnosis of OA induced by exposure to powder paint containing aluminum hydroxide. The patient changed her position in the company and was no longer exposed to powder paint. Her symptoms resolved.

OA has previously been described in smelters and welders in the aluminum industry, as well as in factories producing aluminum salts [4-6]. Exposure to fluorides or aminoethyl

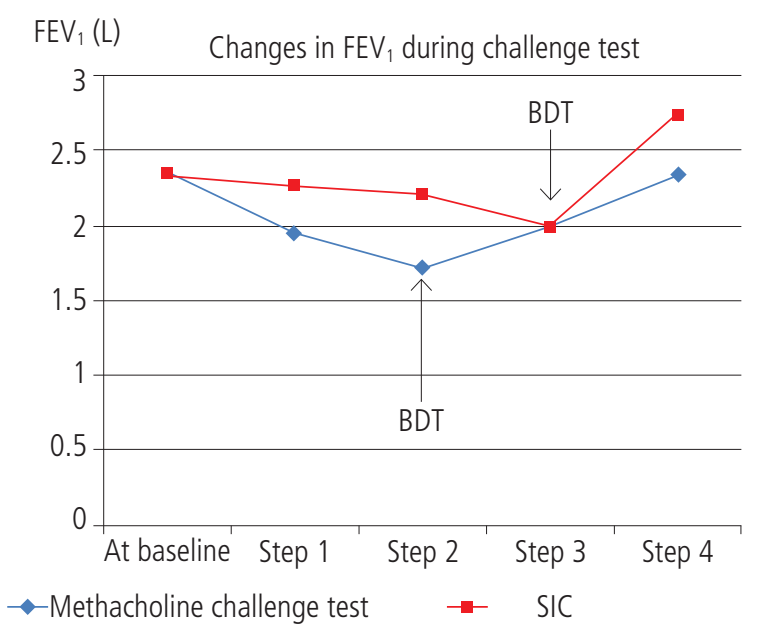

Figure. Changes in $\mathrm{FEV}_{1}$ during challenge tests. FEV1 indicates forced expiratory volume in 1 second; SIC, specific inhalation challenge; BDT: bronchodilator therapy. ethanolamine have been reported to be possible causes of reactions in aluminum smelters $[4,6]$, and several data show that aluminum can cause asthmatic reactions even in the absence of these products [4,7]. To our knowledge, OA induced by exposure to aluminum hydroxide has not previously been reported.

Aluminum hydroxide can take the form of gibbsite, which is amphoteric and has a low molecular weight (LMW, $0.078 \mathrm{kDa})$. The mechanism responsible for the induction of asthma in the present case is still unknown. Some studies have suggested that LMW agents can act as haptens and induce an IgE sensitization response, and other data point to $\mathrm{T}$ lymphocyte--mediated hypersensitivity reactions [8]. The patient in the present study did not experience immediate skin reactivity to powder paint containing aluminum hydroxide.

The case we describe shares several typical characteristics of the LMW-OA phenotype with recent reports [9], namely, absence of atopy and other work-related diseases (eg, rhinitis, conjunctivitis, and urticaria), high AHR, paucigranulocytic inflammatory sputum profile, and normal FeNO level. The LMW-OA phenotype is currently associated with a higher prevalence of late asthmatic reaction on SIC, although the reaction was early in the present case. SIC did not significantly increase FeNO level, which is also described more frequently in this phenotype $[9,10]$. The postchallenge increase in the sputum eosinophil count was significant and similar to the value reported by previous studies [9], thus confirming the switch from the paucigranulocytic pattern to the eosinophilic inflammatory pattern induced by exposure to the causal agent. These data suggest that the sputum eosinophil count could be a better predictive biomarker of OA than FeNO level.

We report a case of OA induced by a powder paint that is rarely used in the automotive industry. In the absence of other causal agents such as triglycidyl isocyanurate or organic acid anhydrides in powder paint, aluminum hydroxide seems to be the most likely allergen.

The patient was not directly exposed to the causal agent because she did not work in the production sector. A detailed history focusing on occupational exposures and the temporal relationship between exposure and symptom onset led us to suspect and subsequently confirm OA.

The diagnosis of OA remains challenging for clinicians. It should be based on a rigorous stepwise approach and better standardization and generalization of diagnostic criteria for OA, including SIC and biomarkers.

\section{Funding}

The authors declare that no funding was received for the present study.

\section{Conflicts of Interest}

The authors declare that they have no conflicts of interest.

\section{References}

1. Muñoz X, Cruz MJ, Bustamante $V$, Lopez-Campos JL, Barreiro E. Work-related asthma: diagnosis and prognosis of 
immunological occupational asthma and work-exacerbated asthma. J Investig Allergol Clin Immunol. 2014;24:396-405.

2. Suojalehto H, Sastre J, Merimaa E, Lindström I, Suuronen K. Occupational Asthma From Epoxy Compounds. J Allergy Clin Immunol Pract. 2019;7:191-8.

3. Blomqvist $A$, Düzakin-Nystedt $M$, Ohlson $C-G$, Andersson $L$, Jönsson B, Nielsen J, et al. Airways symptoms, immunological response and exposure in powder painting. Int Arch Occup Environ Health. 2005;78:123-31.

4. Vandenplas O, Delwiche JP, Vanbilsen ML, Joly J, Roosels D. Occupational asthma caused by aluminium welding. Eur Respir J. 1998;11:1182-4.

5. Kezunović LC. Prevalence of respiratory symptoms and spirometric values in aluminium potroom workers. Arh Hig Rada Toksikol. 2008;59:89-95.

6. Kongerud J, Søyseth V. Respiratory disorders in aluminum smelter workers. J Occup Environ Med. 2014;56:S60-70.

7. Park HS, Uh ST, Park CS. Increased neutrophil chemotactic activity is noted in aluminum-induced occupational asthma. Korean J Intern Med. 1996;11:69-73.

8. Quirce S, Sastre J. Occupational asthma: clinical phenotypes, biomarkers, and management. Curr Opin Pulm Med. 2019;25:59-63.

9. Vandenplas O, Godet J, Hurdubaea L, Rifflart C, Suojalehto $H$, Wiszniewska $M$, et al. Are high- and low-molecularweight sensitizing agents associated with different clinical phenotypes of occupational asthma? Allergy. 2018;74:26172.

10. Sastre J, Costa C, del Garcia Potro M, Aguado E, Mahillo I, Fernández-Nieto $\mathrm{M}$. Changes in exhaled nitric oxide after inhalation challenge with occupational agents. J Investig Allergol Clin Immunol. 2013;23:421-7.

Manuscript received December 19, 2018; accepted for publication March 29, 2019.

Angelica Tiotiu

Department of Pulmonology, University Hospital of Nancy

9 Rue du Morvan

54500 Vandoeuvre-les-Nancy, France

E-mail: angelica.tiotiu@yahoo.com 